\title{
ASPECTOS ANATÔMICOS E FUNCIONAIS DO APARELHO REPRODUTOR DE PARASTACUS BRASILIENSIS (VON MARTENS) (CRUSTACEA, DECAPODA, PARASTACIDAE)
}

\author{
Alexandre Oliveira de Almeida ${ }^{1}$ \\ Ludwig Buckup ${ }^{1}$
}

\begin{abstract}
ANATOMICAL AND FUNCTIONAL ASPECTS OF THE REPRODUCTIVE SYSTEM of PaRastacus bRasiliensis (Von Martens) (Crustacea, DeCapoda, Parastacidae). The absence of morphological external characteristics that allow the recognition of the sex as well as the presence of both male and female gonopores in the same animal [except in some sexual forms of Parastacus nicoleti (Philippi, 1882)] gives rise to the hypothetical existence of some form of hermaphroditism in crayfishes belonging to the genus Parastacus Huxley, 1879. Specimens of Parastacus brasiliensis (von Martens, 1869) were collected in a rivulet at Mariana Pimentel municipality, Rio Grande do Sul, Brazil. In the laboratory they were reared and dissected. The results suggest that $P$. brasiliensis may be a sequential hermaphroditic species, but male and female gonadal tissues were not simultaneously present in the analized samples. In testes and ovaries two pairs of genital ducts are present; that connect, respectively, to the gonopores on the coxae of the fifth and the third pairs of pereiopods. In the females only the apertures and anterior ducts seem to be functional, while in the males only the apertures and posterior ducts may be functional. The existence of different degrees of obstruction in the female genital apertures and different degrees of projection in the male genital apertures was observed. The aspect of the gonopores were used to recognize, externally, the sex of animals.

KEY WORDS. Parastacidae, Parastacus, brazilian crayfish, reproductive system, hermaphroditism
\end{abstract}

A família Parastacidae inclui os crustáceos límnicos conhecidos pela designação popular de "lagostins de água doce" do Hemisfério Sul, com representantes atuais em Madagascar, Oceania e América do Sul (Região Neotropical) (HoBBS 1988). Neste último continente, a família está representada pelos gêneros Parastacus Huxley, 1879 e Samastacus Riek, 1971. O gênero Parastacus inclui oito espécies, das quais seis ocorrem em território brasileiro, com uma distribuição restrita aos estados do Rio Grande do Sul e Santa Catarina (BUCKUP \& RosSI 1980).

A importância de seu estudo está relacionada, entre outros aspectos, com a sua potencialidade para programas de carcinicultura, pois trata-se de um grupo de espécies inteiramente adaptado às condições climáticas e limnológicas do Brasil meridional, tendo condições de repetir o sucesso já alcançado com o cultivo de lagostins no Hemisfério Norte. Na América do Sul, entretanto, o cultivo do lagostim ainda não foi tentado. Alega-se falta de informações sobre algumas bases biológicas essenciais para iniciativas zootécnicas, em especial sobre seu ciclo reprodutivo.

1) Departamento de Zoologia, Instituto de Biociências, Universidade Federal do Rio Grande do Sul. Avenida Paulo Gama, 90040-060 Porto Alegre, Rio Grande do Sul, Brasil. 
Nas famílias Astacidae e Cambaridae, do Hemisfério Norte, o principal caráter externo de dimorfismo sexual é a forma dos pleópodos, especialmente os do primeiro somito abdominal, que são vestigiais nas fêmeas e modificados em órgãos copulatórios nos machos. As aberturas genitais femininas situam-se nos coxopoditos do terceiro par de pereiópodos e as masculinas nos coxopoditos do quinto par de pereiópodos (Holdich \& REEVE 1988). Na terceira família, Parastacidae, nem machos, nem fêmeas, possuem pleópodos no primeiro somito abdominal, nem mesmo vestigiais (HoRWITZ 1988). Além disso, de acordo com RIEK (1972), dos 14 gêneros desta família, Parastacus é o único em que as aberturas genitais masculinas e femininas existem nos mesmos indivíduos em todas as espécies, o que tem sido um obstáculo significativo para a identificação do sexo dos animais. No entanto, os resultados obtidos por RUDOLPH (1995), em P. nicoleti (Philippi, 1882), contrariam a afirmativa de RIEK (1972), pois nesta espécie poucos indivíduos apresentam dois pares de aberturas genitais. BUCKUP \& RosSI (1980) em sua revisão dos Parastacidae brasileiros, trabalharam com a hipótese de que animais com os poros femininos dos coxopoditos do terceiro par de pereiópodos obstruidos por material epicuticular rígido, aparentemente sem funcionalidade, seriam machos e que animais com tais poros obstruidos com material epicuticular menos rígido seriam fêmeas.

VON MARTENS (1869), ao descrever brasiliensis e pilimanus, ainda no gênero Astacus, como espécies novas, já observara a presença de gonóporos femininos nos coxopoditos do terceiro par de pereiópodos de machos. FAXON (1898) também verificou a ocorrência simultânea de dois pares de gonóporos nos mesmos indivíduos de $P$. varicosus Faxon, 1898, P. saffordi Faxon, 1898, P. defossus Faxon, 1898 e P. hassleri Faxon, 1898.

LÖNNBERG (1898), investigando as relações dos referidos poros com as estruturas internas do aparelho reprodutor em $P$. hassleri [atualmente $P$. pugnax (Poeppig, 1835)], do Chile, constatou que, embora existissem gônadas próprias de cada sexo, cada uma apresentava um par de dutos genitais supranumerário. Realizando cortes nos testículos, encontrou corpos semelhantes a células germinais femininas. Este quadro levou o autor a emitir a hipótese da existência hermafroditismo parcial em $P$. hassleri e nas demais espécies do gênero em que os dois pares de aberturas genitais tinham sido observados, sem, no entanto, avançar na pesquisa sobre esta possibilidade, devido ao mau estado de preservação dos espécimes dissecados. HAY (1905), examinando espécimes de Parastacus do U.S. National Museum, assume a mesma posição de LÖNNBERG (1898).

HoRwITz (1988) relata a ocorrência de alta proporção de indivíduos com gonóporos de ambos os sexos, nas populações dos parastacídeos australianos dos gêneros Engaeus Erichson, 1846 e Engaewa Riek, 1967, que segundo RIEK (1972), são os dois gêneros mais próximos, filogeneticamente, a Parastacus. HORWITZ também verificou que as fêmeas de Engaeus, para se tornarem funcionalmente reprodutivas, sofrem descalcificação nos seus poros genitais. Salienta, ainda, que a fêmea conserva a forma funcional de seus poros genitais durante os períodos de inatividade reprodutiva, o que conferiria ao animal uma teórica capacidade permanente de oviposição. 
FONTOURA \& BUCKUP (1989b) verificaram que a reprodução em Parastacus brasiliensis tem duas fases distintas. A primeira, que vai de setembro a janeiro, é caracterizada pela postura e incubação dos ovos junto aos pleópodos, com ponto médio, na amostra estudada, em 11 de novembro. A segunda ocorre após a eclosão dos juvenis, quando estes permanecem aderidos aos pleópodos da fêmea. Esta fase vai de novembro a fevereiro, com ponto médio, na amostra observada, em 22 de dezembro.

RudolPH (1995), tendo examinado $P$. nicoleti, do Chile, descreveu o primeiro caso de hermafroditismo no gênero, do tipo sequencial protândrico, que segundo WARNER (1975) é a situação em que o indivíduo muda do sexo masculino para o feminino em algum ponto da sua vida. $\mathrm{O}$ autor emite a hipótese de que $\mathrm{o}$ mesmo processo poderia ocorrer em P. pugnax, do Chile e nas espécies brasileiras e uruguaias de Parastacus. Estudos morfológicos e histológicos do aparelho reprodutor das formas sexuais encontradas, mostraram a existência de dois tipos sexuais básicos: fêmeas primárias e hermafroditas protândricos. As primeiras, não possuem traços de tecido gonadal masculino e vasos deferentes, nem aberturas genitais masculinas. Os hermafroditas protândricos passam por uma fase masculina, onde os indivíduos apresentam um par de vasos deferentes e aberturas genitais funcionais no quinto par de pereiópodos. Os dois tipos femininos, resultantes de uma mudança de sexo, têm genitálias internas com traços masculinos. Um dos tipos (tipo 1) sofre um gradual processo de feminização (onde um dos gonóporos masculinos permanece), enquanto que o outro (tipo 2), mais raro, é derivado de uma rápida feminização de grandes espécimes ainda em fase masculina, permanecendo, neste caso, o par de aberturas genitais masculinas. A única forma presente em todos os tamanhos de classe foi a hermafrodita protândrica em fase masculina. Quando isto acontece, ou seja, quando não há tamanho crítico para a mudança de sexo, a protandria é denominada parcial (GHERARDI \& CALLONI 1993).

No presente trabalho visou-se buscar o conhecimento da morfologia e do funcionamento do aparelho reprodutor dos parastacídeos brasileiros e encontrar respostas para a questão da existência de dois pares de aberturas genitais nos mesmos indivíduos de Parastacus. O exame da morfologia interna, em especial do aparelho reprodutor, no contexto da existência dos dois pares de poros genitais, foi incluido nas investigações.

A espécie utilizada para tal foi P. brasiliensis (von Martens, 1869), um lagostim de hábito escavador e de atividade preferencialmente noturna (FONTOURA \& BUCKUP 1989a). Os indivíduos desta espécie são encontrados em pequenos ambientes lóticos do Rio Grande do Sul, como arroios, riachos e fontes (BUCKUP \& Rossi 1980), sob detritos vegetais que se acumulam nos remansos e baixios destes ambientes ou no interior de tocas por eles mesmos construidas nas barrancas marginais, acima do nível da água dos arroios (FrIEs 1984).

\section{MATERIAL E MÉTODOS}

Os exemplares de Parastacus brasiliensis foram obtidos em trabalhos de campo realizados entre dezembro de 1994 e novembro de 1995, no Arroio Negro (Bacia do Rio Guaíba), um pequeno sistema lótico de substrato areno-pedregoso 
(FONTOURA \& BUCKUP 1989a), situado numa reserva biológica particular com mata subtropical nativa localizada no município de Mariana Pimentel, a $30^{\circ} 20^{\prime} 39^{\prime \prime} \mathrm{S}$ e $51^{\circ} 22^{\prime} 39 " \mathrm{~W}$, no Rio Grande do Sul.

As coletas foram realizadas nos dias 14-XII-1994, 17-III, 25-VII, 14-IX e 09-XI-1995, nas quais se obteve $13,6,9,11$ e 7 animais, respectivamente. No laboratório, os animais foram marcados através do corte de um dos ramos uropodais e também pelo corte de pleópodos e cultivados em aquários. As fêmeas ovígeras foram mantidas isoladas com a finalidade de evitar conflitos com os outros animais, pois muitas vezes observou-se comportamento agressivo nos contatos intraespecíficos.

A carapaça dos animais foi medida com um paquímetro $(0,1 \mathrm{~mm})$. $\mathrm{O}$ aspecto dos gonóporos foi analisado semanalmente com o auxílio de um microscópio estereoscópico Stemi SV 8 Zeiss equipado com câmara clara, com o objetivo de identificar possíveis alterações morfológicas associáveis a eventos do ciclo reprodutivo. A morfologia dos poros de exemplares pertencentes à coleção do laboratório de Carcinologia, e dos juvenis eclodidos em laboratório, também foi observada. Os gonóporos femininos foram classificados quanto ao seu grau de obstrução, no sentido das hipóteses de BUCKUP \& ROsSI (1980), enquanto que os masculinos foram classificados de acordo com seu grau de projeção. Outros aspectos da biologia dos animais, como ecdises e oviposições, também foram anotados.

Os espécimes foram dissecados conforme a técnica sugerida por KÜKENTHAL et al. (1969). Os aparelhos reprodutores masculino e feminino foram fotografados com uma máquina fotográfica acoplada ao microscópio estereoscópico.

As peças anatômicas retiradas para fins de exame histológico foram fixadas em Bouin por 24 horas. Após, o fixador foi trocado por álcool $70 \%$, onde as peças permaneceram, por no mínimo, 24 horas. Seguiram-se as etapas de desidratação, diafanização e impregnação por parafina.

As gônadas foram seccionadas transversalmente. Nos ovários os cortes foram de 7 micrômetros, enquanto que para os testículos, seguiu-se o trabalho de WORD \& HOBBS (1958), que realizaram cortes de $20 \mu \mathrm{m}$ de espessura. A técrica de coloração utilizada foi o $\mathrm{H}$-E. O registro fotográfico dos cortes foi realizado com um fotomicroscópio Nikon modelo Optiphot-2.

\section{RESULTADOS E DISCUSSÃO}

Os animais coletados mediram de 15,6 a $42,6 \mathrm{~mm}$ de comprimento de carapaça. Uma fêmea portadora de juvenis e quatro fêmeas ovígeras foram coletadas em 14-XII-94 e 09-XI-95, respectivamente.

No material coletado e nos exemplares desta espécie da coleção do laboratório de Carcinologia, verificou-se a presença de gonóporos de ambos os sexos nos mesmos indivíduos. Os gonóporos femininos, nos coxopoditos do terceiro par de pereiópodos, possuem um contorno ovalado, enquanto que os masculinos, nos coxopoditos do quinto par de pereiópodos, situam-se no ápice de uma pequena elevação cônica. No entanto, um espécime de $31,6 \mathrm{~mm}$ de comprimento de carapaça, que já vinha sendo cultivado antes da primeira coleta referida, possuia apenas um 
dos gonóporos femininos (o direito), enquanto que o outro era fortemente calcificado. O par masculino era normal. A dissecção deste espécime mostrou que se tratava de um macho.

Nos exemplares dissecados no período de inatividade sexual dos animais, ou seja, de março a agosto, as gônadas, muitas vezes, mostravam-se reduzidas, dificultando a sua identificação. Obteve-se sucesso nas dissecções realizadas durante o período reprodutivo, que vai de setembro a fevereiro. Dos sete exemplares coletados em 09-XI-95, ou seja, bem próximo do ponto médio da fase de incubação (11 de novembro) estimado por FONTOURA \& BUCKUP (1989b), quatro eram fêmeas ovígeras.

Três casos de oviposição ocorreram em laboratório, nos dias 08 e 22-IX-95 e 19-X-95. No momento da oviposição, as fềmeas, agora identificadas como tal com segurança, possuiam $39,8,32,7$ e $30,7 \mathrm{~mm}$, respectivamente. Destes, apenas o primeiro culminou com a eclosão de alguns juvenis, que sobreviveram por pouco tempo. Nos outros dois casos, houve início de diferenciação embrionária, porém as fêmeas ingeriram os ovos antes da eclosão dos juvenis.

Em $P$. brasiliensis as gônadas são torácicas, tubulares e pares, justapostas no plano sagital, com forma e estrutura próprias de cada sexo (Figs 1-2). Tanto os testículos como os ovários têm uma porção anterior vertical, situada atrás do estômago e circundada por parte do hepatopâncreas, e uma posterior horizontal, situada sob o coração e sobre o intestino.
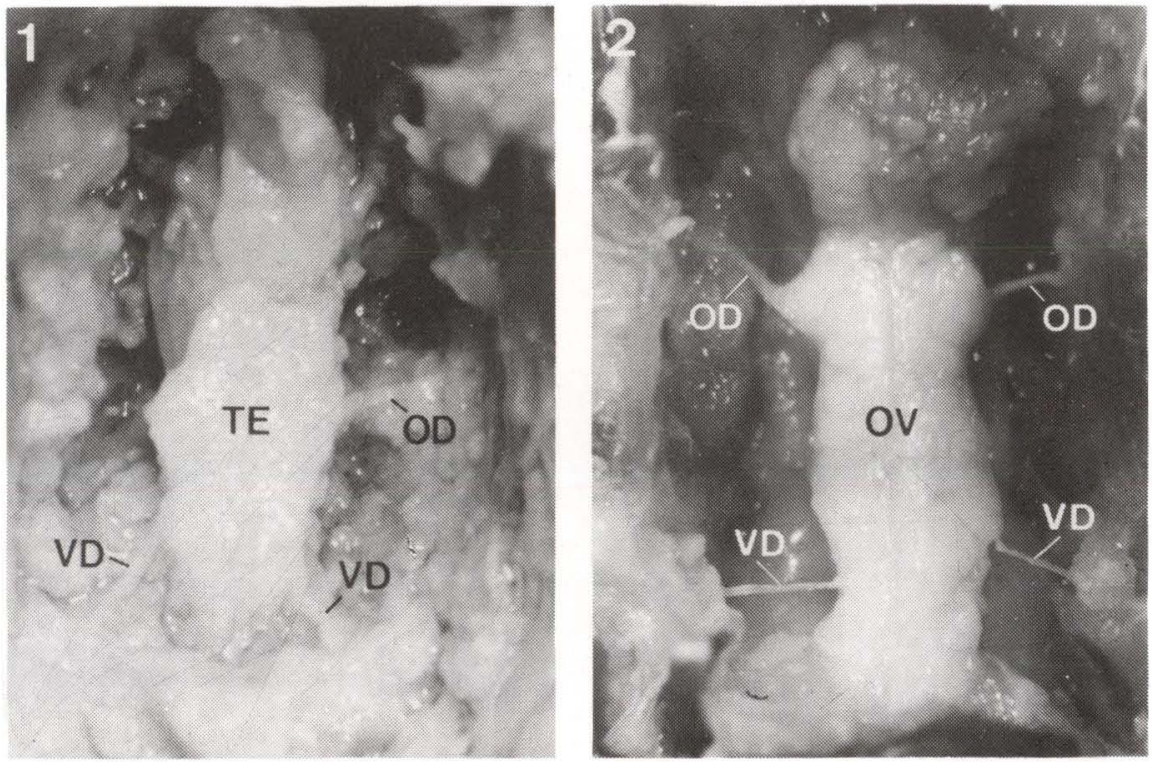

Figs 1-2. Parastacus brasiliensis, vista dorsal da gônada. (1) Masculina; (2) feminina. (OD) Oviduto, (OV) ovários, (TE) testículos, (VD) vasos deferentes. 

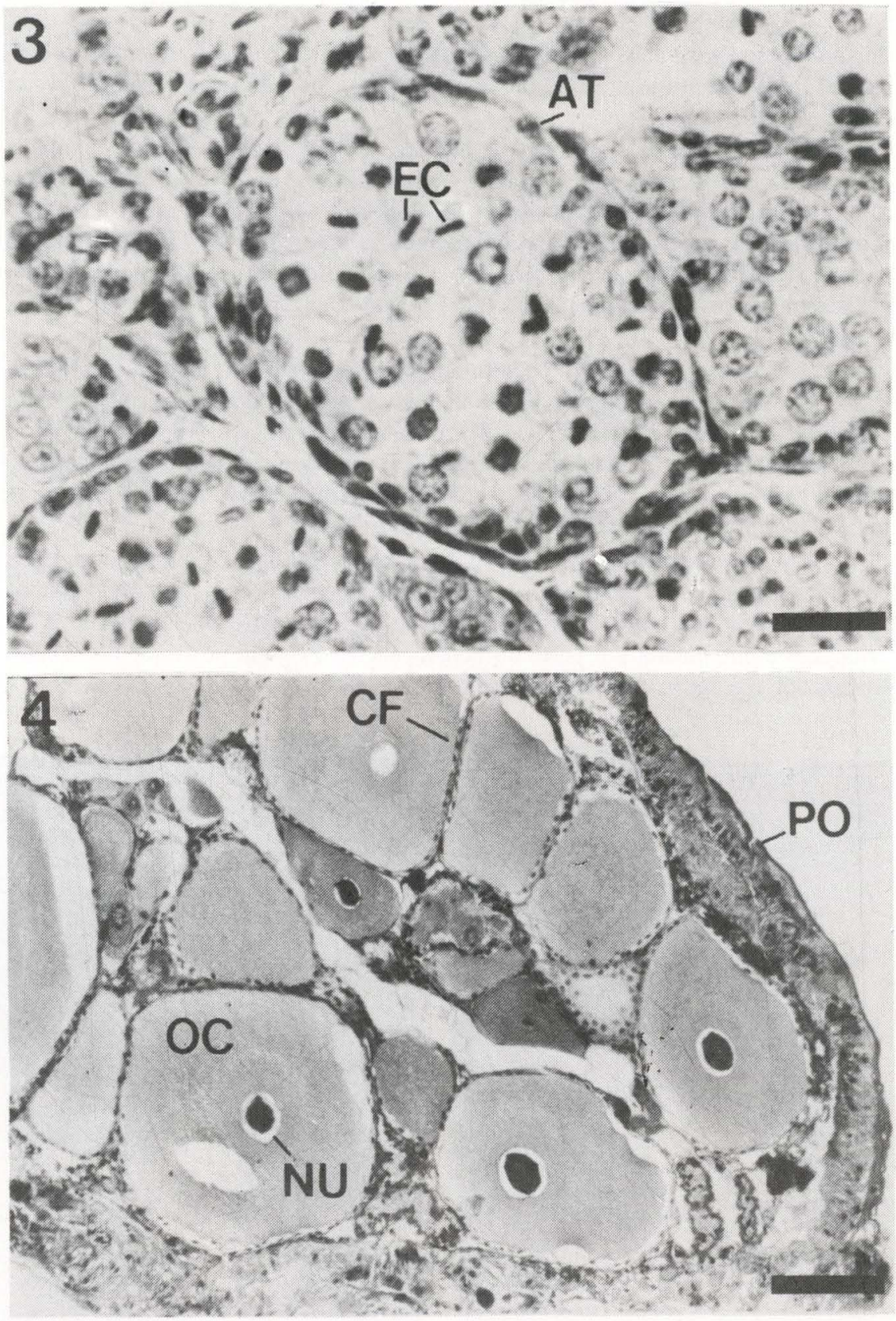

Figs 3-4. Parastacus brasiliensis, secção transversal da gônada. (3) Masculina (barra de calibração $=27 \mu \mathrm{m}$ ); $(4)$ feminina (barra de calibração $=130 \mu \mathrm{m})$. (AT) Ácino testicular, $(\mathrm{CF})$ células foliculares, (EC) espermatócitos em divisão meiótica, (NU) núcleo, (OC) ovócito, (PO) parede ovariana. 
Os testículos têm coloração esbranquiçada (Fig. 1). As preparações histológicas mostraram que as porções horizontal e vertical são compostas por dois túbulos que se conectam lateralmente através de tecido conjuntivo, o que faz com que externamente pareça um órgão único. A histologia dos testículos de $P$. brasiliensis é muito semelhante à de $P$. nicoleti. Eles são formados por uma parede, por túbulos coletores e ácinos testiculares (Fig. 3), no interior dos quais se dá a espermatogênese. A morfologia dos testículos de P. brasiliensis, difere significativamente da morfologia destes órgãos nos Astacidae e Cambaridae. Nestas duas famílias, os testículos são formados por três lobos distintos, dois anteriores e um posterior (WORD \& HobBs 1958; Wielgus 1973; Wielgus-SerafinsKa 1976; Holdich \& ReEve 1988). Nos Cambaridae, os lobos são claviformes, pela presença de pedúnculos na área de conexão entre os três lobos, uma característica morfológica resultante da degeneração dos ácinos testiculares, que aumenta de tamanho com a idade do macho (WORD \& HoBBS 1958; WIELGUS 1973; WIELGUS-SERAFINSKA 1976).

Os ovários têm coloração castanho-escuro durante o período reprodutivo, quando ocupam a maior parte da região torácica (Fig. 2). Percebe-se um sulco mediano ao longo das duas porções gonadais, que representa a área de ligação entre dois ovários através de tecido conjuntivo. O intestino aloja-se num sulco existente na superfície ventral da massa ovariana. Os ovários são formados por uma parede, ovócitos em diversos estágios de maturação e células foliculares (Fig. 4). Sua morfologia também difere da morfologia dos Astacidae e Cambaridae, que têm ovários trilobados (STEPHENS 1952; LOWE 1961; HoldiCH \& REEVE 1988).

Tomando-se por base os resultados do exame de alguns cortes histológicos realizados, verificou-se que as gônadas ou eram femininas, produtoras de ovócitos ou masculinas, produtoras de espermatócitos. Ou seja, não foi encontrada uma organização histológica que pudesse sugerir a produção simultânea de células reprodutivas masculinas e femininas na mesma gônada.

Constatou-se, confirmando LÖNNBERG (1898), a existência constante de dois pares de dutos genitais, que se originam nas regiões laterais da porção horizontal, tanto em testículos como em ovários (Figs 1-2). Observa-se um par anterior (ovidutos), que se direciona aos gonóporos do terceiro par de pereiópodos, e um par posterior (vasos deferentes), que se direciona aos gonóporos do quinto par de pereiópodos.

Observou-se, ainda, que nas fêmeas, durante o período reprodutivo, os gonóporos próprios de seu sexo não estão obstruidos por material epicuticular rígido, estando cobertos por uma fina membrana, possuindo, desta forma, capacidade de oviposição. Esta condição é adquirida após a muda pré-parturial. As fêmeas ovígeras coletadas em campo e as ovígeras obtidas em laboratório, apresentaram gonóporos femininos totalmente desobstruidos. Após a oviposição, observou-se um gradual enrijecimento dos gonóporos femininos, intensificado após a muda pós-parturial, quando o animal perde a capacidade de oviposição. Esta situação contrasta com a observada por HoRwITZ (1988) em Engaeus tuberculatus Clark, 1936 e E. hemicirratulus (Clark, 1936), e por RUDOLPH (1995) em P. nicoleti. Os autores afirmam que as fêmeas destas espécies, uma vez tendo atingido sua morfologia reprodutiva, especialmente tendo seus gonóporos sofrido descalcificação, manteriam seu estado morfológico, inclusive no período de inatividade sexual. 

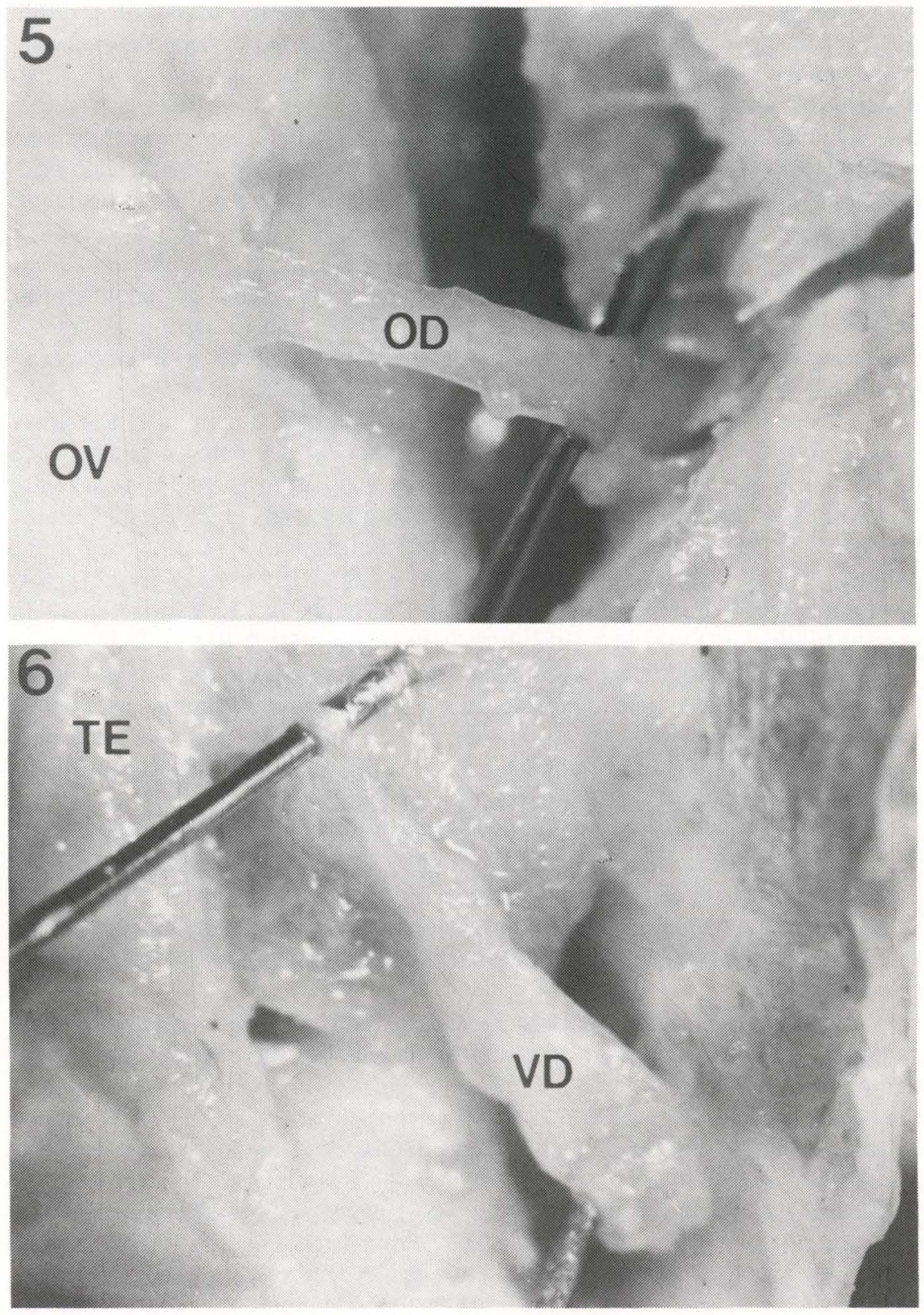

Figs 5-6. Parastacus brasiliensis. (5) Oviduto direito da fêmea; (6) vaso deferente direito do macho. (OD) Oviduto, (OV) ovário, (TE) testículo, (VD) vaso deferente.

Revta bras. Zool. 14 (2): 497 - 509, 1997 
Já nos machos, tanto na fase reprodutiva como na não reprodutiva, os gonóporos do terceiro par de pereiópodos, equivalentes aos do sexo feminino, estão totalmente obstruidos (no máximo sofrendo pequenas descalcificações).

Nas fêmeas, os dutos genitais posteriores e as aberturas do quinto par de pereiópodos têm um diâmetro reduzido, aparentemente insuficiente para a passagem de ovócitos, enquanto que os dutos anteriores (Fig. 5) têm um diâmetro amplo, especialmente nos seus pontos de origem.

Nos machos, os dutos genitais anteriores se mostram muito delgados e translúcidos, o que, juntamente com a obstrução dos gonóporos correspondentes, indicam ausência de funcionalidade de dutos e gonóporos anteriores. Já os dutos posteriores (Fig. 6), têm um diâmetro muito grande em comparação com o dos anteriores, especialmente à medida que se afastam das gônadas. Esta característica dos vasos deferentes permanece, pelo menos nos primeiros meses após o período reprodutivo, quando, mesmo com as gônadas reduzidas, permitem que se identifique um exemplar como macho.

$\mathrm{O}$ acompanhamento da variação do aspecto dos gonóporos dos indivíduos em laboratório possibilitou o reconhecimento do sexo dos indivíduos com grande porcentagem de sucesso. No início da presente investigação foi adotado o critério da morfologia dos gonóporos femininos para o reconhecimento do sexo dos espécimes, sensu BUCKUP \& ROSSI (1980). Verificou-se a existência de três graus de obstrução: ausente, parcial e total. No entanto, a existência de machos com pequenas descalcificações nestes gonóporos poderia levar a dúvidas na identificação do sexo. Assim, os gonóporos masculinos ganharam atenção especial. Foram encontradas diferenças na projeção destes gonóporos entre os indivíduos. Quatro graus de projeção foram observados: inexistente, pequena, média e grande. Com a análise em conjunto dos dois pares de gonóporos, observou-se que as fêmeas apresentavam gonóporos femininos com obstrução ausente (Fig. 7A) ou parcial (Fig. 8A) e gonóporos masculinos com projeção inexistente (Fig. 7B) ou pequena (Fig. 8B); os machos, apresentavam gonóporos femininos totalmente obstruidos (Figs 9A-10A) e gonóporos masculinos com projeção média (Fig. 9B) e grande (Fig. 10B).

A coexistência de dois pares de dutos genitais é uma característica morfológica reprodutiva típica de uma espécie hermafrodita sequencial, porém não se encontrou alguma gônada em fase de transição entre um sexo e outro, quando os tecidos gonadais femininos e masculinos estão presentes simultaneamente.

RUDOLPH (1995) diz que os estudos de morfologia gonadal e/ou de histologia nas espécies do gênero têm sido realizados em poucos exemplares de grandes tamanhos, onde a mudança de sexo já possa ter ocorrido. O número de exemplares utilizados por aquele autor em em suas investigações (473) é muito superior ao utilizado nesta pesquisa (46). No entanto, 46 exemplares, todos com comprimento de carapaça acima dos $15 \mathrm{~mm}$, mostraram dois pares de aberturas genitais, conforme já foi relatado, mas em todos os exemplares apenas um dos poros mostrou ser aparentemente funcional. Os animais em estágio juvenil (a partir dos $9 \mathrm{~mm}$ de comprimento de carapaça), embora em número pouco representativo, sempre mostraram dois pares de aberturas genitais. Estas observações, mesmo baseadas em poucos exemplares, indicam que se $P$. brasiliensis tiver um polimorfismo sexual 
como o de $P$. nicoleti, este não pôde ser reconhecido pelo exame de sua genitália externa. A presença de dois pares de gonóporos parece ser a condição normal para P. brasiliensis.

A
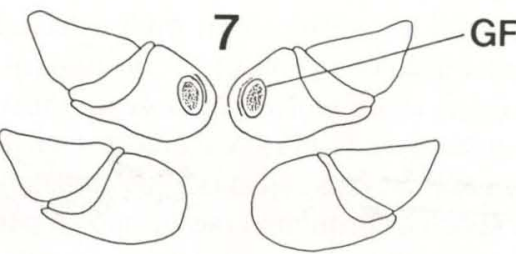

GF

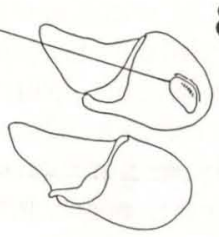

8
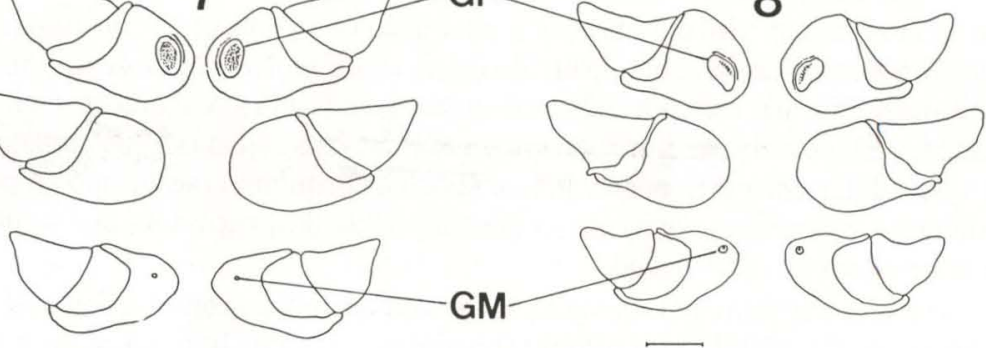

A
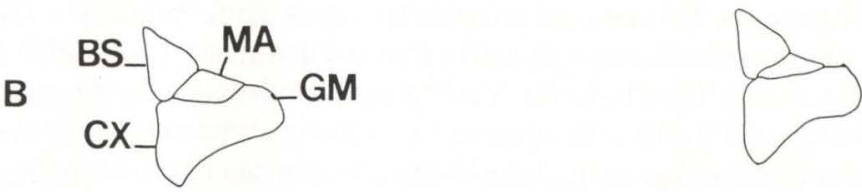

B

A

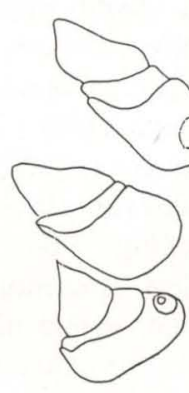

9
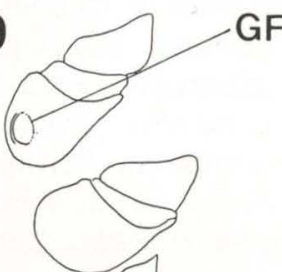

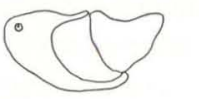

\section{A}

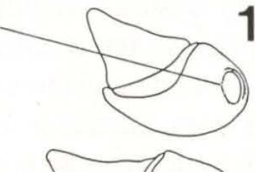

10
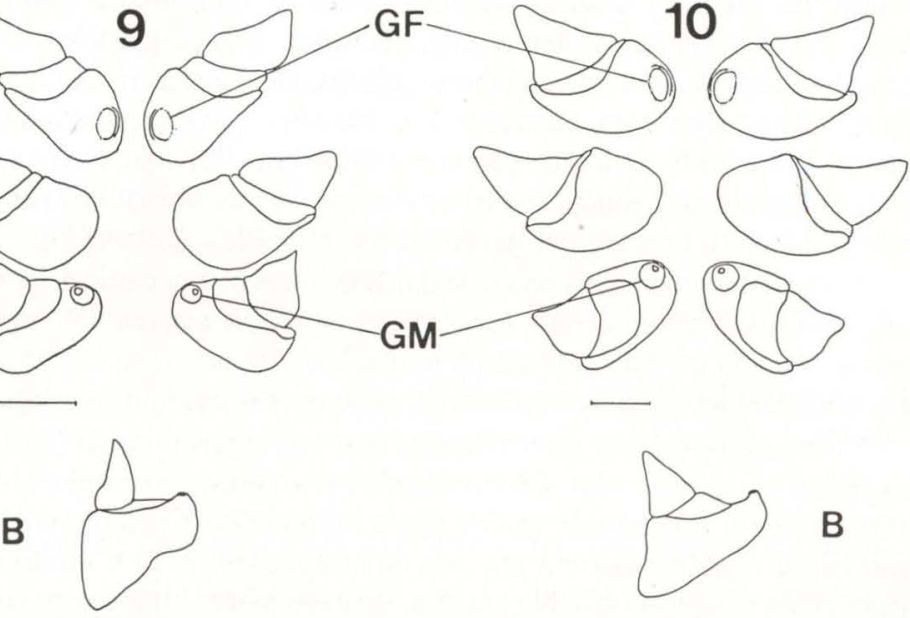

B

Figs 7-10. Parastacus brasiliensis. (7A-8A) Vista ventral de fêmeas; (9A-10A) vista ventral de machos; (7B-8B) vista lateral do coxopodito do quinto par de pereiópodos de fêmeas; (9B-10B) vista lateral do coxopodito do quinto par de pereiópodos de machos. (BS) Basipodito, (CX) coxopodito, (GF) gonóporos femininos, (GM) gonóporos masculinos, (MA) membrana articular. Escalas: $0,25 \mathrm{~mm}$. 
Quanto à genitália interna, a presença dos dois pares de dutos genitais foi constante. As fêmeas mostraram um quadro similar ao encontrado na forma hermafrodita protândrica em fase feminina tipo 2 de $P$. nicoleti, onde o ovário possui um par de vasos deferentes não funcionais. Machos de $P$. brasiliensis com comprimento de carapaça superior a $25 \mathrm{~mm}$ foram examinados e seus testículos sempre possuiam ovidutos não funcionais. Como nesta pesquisa o número amostral foi pequeno, a hipótese da existência de polimorfismo sexual nas genitálias internas não pode ser descartada.

Parastacus nicoleti, do Chile, é uma espécie fossorial, como as espécies brasileiras-periplatinas $P$. pilimanus (Von Martens, 1869) e $P$. defossus, habitando tocas de até $2 \mathrm{~m}$ de profundidade, onde vivem em grupos. Seu abdome é relativamente pequeno, tendo reduzida a sua capacidade natatória o que, juntamente com a presença de barreiras (tipos de solo) e a ausência de rotas, reduziu a possibilidade de dispersão, criando restrições ao fluxo interpopulacional de genes e reduzindo, conseqüentemente, a variabilidade genética. O hermafroditismo, nesta espécie, segundo RUDOLPH (1995), seria, provavelmente, uma adaptação a estas inconveniências, através do aumento do número de fêmeas reprodutivas na população. A redução do abdome em função do hábito seria compensada pela aquisição dos caracteres sexuais secundários que têm por finalidade aumentar a superfície e o volume do abdome das fêmeas. Além disso, os estudos mostraram a existência de uma correlação positiva entre o tamanho das fêmeas e o número de ovos, ou seja, fêmeas grandes produzem um número maior de ovos.

Ao contrário de $P$. nicoleti, $P$. brasiliensis é uma espécie que prefere pequenos ambientes lóticos. Devido a isto, e também por ter maior dependência com relação à água, sua capacidade de dispersão é igualmente pequena. Seu abdome, conforme observado em laboratório, é muito utilizado para a natação, sendo bem desenvolvido. É provável que não vivam em grupos, pois os juvenis são freqüentemente encontrados fora das tocas, sob detritos vegetais acumulados. RUDOLPH (1995) pôde emitir hipóteses sobre a razão do hermafroditismo de $P$. nicoleti porque dispôs de um grande número amostral, coletou exemplares de todos os grupos etários, realizou estudos morfométricos e analisou a estrutura social da espécie. Para que se possa comparar $P$. brasiliensis com $P$. nicoleti, tudo isto deve ser levado em conta nas próximas investigações.

Os resultados aqui apresentados indicam que existem diferenças entre as genitálias externas de $P$. brasiliensis e $P$. nicoleti. Os hábitos de vida destas espécies são diferentes, o que talvez possa explicar estas diferenças. Quanto à genitália interna, os resultados obtidos representam uma base biológica útil para novas investigações, especialmente quanto ao comportamento dos aparelhos genitais ao longo do tempo, des đo estágio juvenil, naquela que deve ser a nova e definitiva etapa para se determinar o tipo de sexualidade de Parastacus brasiliensis. 


\section{REFERÊNCIAS BIBLIOGRÁFICAS}

Buckup, L. \& A. Rossi. 1980. O gênero Parastacus no Brasil (Crustacea, Decapoda, Parastacidae). Rev. Brasil. Biol. 40 (4): 663-681.

FAXON, W. 1898. Observations on the Astacidae in the United States National Museum and in the Museum of Comparative Zoology, with descriptions of new species. Proc. U.S. Nat. Mus. 20: 643-694.

FonTOURA, N.F. \& L. BUCKUP. 1989a. O crescimento de Parastacus brasiliensis (von Martens, 1869) (Crustacea, Decapoda, Parastacidae). Rev. Brasil. Biol. 49 (4): 897-909.

1989b. Dinâmica populacional e reprodução em Parastacus brasiliensis (von Martens, 1869) (Crustacea, Decapoda, Parastacidae). Rev. Brasil. Biol. 49 (4): 911-921.

FRIES, B.G. 1984. Observações sobre o "lagostim de água doce" Parastacus brasiliensis (von Martens, 1869) em condições de cultivo experimental em laboratório (Crustacea, Decapoda, Parastacidae). Rev. Brasil. Biol. 44 (4): 409-416.

GHERARDI, F. \& C. CALloni. 1993. Protandrous hermaphroditism in the tropical shrimp Athanas indicus (Decapoda: Caridea), a symbiont of sea urchins. Jour. Crust. Biol. 13 (4): 675-689.

HAY, W.P. 1905. Instances of hermaphroditism in crayfishes. Smithson. misc. Collns 48 (2): 222-228.

HoBBS JR., H.H. 1988. Crayfish distribution, adaptive radiation and evolution, p.52-82. In: D.M. HOLDICH \& R.S. LOWERY (Eds). Freshwater crayfish: biology, management and exploration. Portland, Timber Press, VIII+498p.

HoLDICH, D.M. \& I.D. REEVE. 1988. Functional morphology and anatomy, p.11-51. In: D.M. HOLDICH \& R.S. LOWERY (Eds). Freshwater crayfish: biology, management and exploitation. Portland, Timber Press, VIII+498p.

HoRwITZ, P. 1988. Secondary sexual characteristics of females of the freshwater crayfish genus Engaeus (Decapoda, Parastacidae). Crustaceana 54 (1): 25-32.

KÜKenthal, W.; E. Matthes \& M. Renner. 1969. Guia de Trabalhos Práticos em Zoologia. Coimbra, Atlântida Editora, XVI+473p.

LÖNNBERG, E. 1898. Some biological and anatomical facts concerning Parastacus. Zool. Anz. 21: 345-352.

LOWE, M.E. 1961. The female reproductive cycle of the crayfish Cambarellus shufeldti: the influence of environmental factors. Tulane Stud. Zool. 8 (6): 157-176.

RIEK, E. 1972. The phylogeny of the Parastacidae (Crustacea, Astacoidea), and description of a new genus of australian freshwater crayfishes. Aust. Jour. Zool. 20: 369-389.

RUDOLPH, E.H. 1995. Partial protandric hermaphroditism in the burrowing crayfish Parastacus nicoleti (Philippi, 1882) (Decapoda, Parastacidae). Jour. Crust. Biol. 15 (4): 720-732.

STEPHENS, G.J. 1952. Mechanisms regulating the reproductive cycle in the cray fish, 
Cambarus. I. The female cycle. Physiol. Zool. 25 (1): 70-84.

VON MARTENS, E. 1869. Südbrasilianische Süss-und Brackwasser-Crustaceen nach den Sammlungen des Dr. Reinh. Hensel. Arch. Naturgesch. 35 (1): 1-37.

WARNER, R.R. 1975. The adaptive significance of sequential hermaphroditism in animals. Amer. Nat. 109: 61-82.

WIELGUS, E. 1973. Structure of the testes in indigenous crayfishes. Folia morph. 32 (1): 115-124.

Wielgus-SERAFINSKA, E. 1976. Morphological and histological changes in the male gonad of the american crayfish Orconectes limosus (Rafinesque) in the annual cycle. Acta biol. cracov., Series Zoologia, 19: 87-105.

WORD JR., B.H. \& H.H. HOBBS JR. 1958. Observations on the testis of the crayfish Cambarus montanus acuminatus Faxon. Trans. Amer. microsc. Soc. 77 (4): 435-450.

Recebido em 29.IX.1996; aceito em 25.VII.1997. 